\title{
CD44v/CD44s expression patterns are associated with the survival of pancreatic carcinoma patients
}

\author{
Zhonghu Li ${ }^{\dagger}$, Kai Chen ${ }^{\dagger}$, Peng Jiang, Xi Zhang, Xiaowu Li ${ }^{*}$ and Zhihua Li
}

\begin{abstract}
Background and purpose: CD44 variants have been associated with tumor invasion and metastasis, but CD44 expression patterns have not been systematically investigated in pancreatic carcinoma. This study systematically investigated whether CD44 expression patterns are involved in pancreatic carcinoma metastasis and prognosis.

Methods: We applied primers specific for all CD44 variants and CD44s to analyze the expression patterns of CD44 (CD44v2-CD44v10 and CD44s) using quantitative real-time PCR (qRT-PCR). We then further evaluated their roles in pancreatic carcinoma metastasis and prognosis using clinical survival analysis.

Results: Increased CD44v expression and decreased CD44s expression were found in metastatic pancreatic carcinoma in three different cell lines and in human tumor tissue. Clinical analysis showed that CD44v6 ${ }^{+}$and $\mathrm{CD} 44 \mathrm{v} 9^{+}$were correlated with lymph node metastasis, liver metastasis and TNM stage. However, CD44s ${ }^{-}$was associated with liver metastasis, tumor differentiation and TNM stage. Survival analysis showed that patients with $\mathrm{CD} 44 \mathrm{v} 6^{+} / \mathrm{CD} 44 \mathrm{~s}^{-}$or

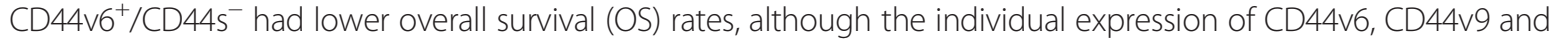
CD44s was also related to decreased OS rates. Univariate analysis showed that lymph node metastasis; vessel invasion; hepatic metastases; TNM stage; and individual or co-expression of CD44v6, CD44v9 and CD44s were risk factors affecting survival. Multivariate analysis showed that $\mathrm{CD} 44 \mathrm{v} 6^{+} / \mathrm{CD}_{4} 4 \mathrm{~s}^{-}$was an independent predictor of survival.

Conclusions: We found that $\mathrm{CD} 44 \mathrm{v} 6^{+}, \mathrm{CD} 44 \mathrm{v} 9^{+}$and $\mathrm{CD} 44 \mathrm{~s}^{-}$were associated with pancreatic carcinoma metastasis and progression and that $\mathrm{CD} 44 \mathrm{v} 6^{+} / \mathrm{CD} 44 \mathrm{~s}^{-}$was an independent risk factor affecting survival in pancreatic carcinoma. Therefore, the different expression patterns of CD44v/CD44s may determine pancreatic carcinoma prognosis.
\end{abstract}

Virtual slides: The virtual slide(s) for this article can be found here: http://www.diagnosticpathology.diagnomx.eu/vs/ 1579257224116287.

Keywords: CD44, CD44v, CD44s, Pancreatic carcinoma, Survival

\section{Background}

Pancreatic carcinoma (PCa) is undoubtedly the most aggressive and the deadliest cancer [1]. Early metastasis to regional lymph nodes or hematogenous spread to distant organs is largely responsible for the lowest 5-year survival rate (less than 5\%) [2,3]. Numerous molecules have been described and extensively investigated for their potential roles in the tumorigenesis and progression of PCa; CD44 is the most important of these molecules.

\footnotetext{
*Correspondence: lixw1966@163.com; tmmulizhihua@163.com ${ }^{\dagger}$ Equal contributors

Department of Hepatobiliary Surgery Institute, Southwest Hospital, Third Military Medical University, 30 Gaotanyan Street, Shapingba District, Chongqing 400038, China
}

CD44 is quite complicated. This molecule is encoded by 20 exons and undergoes extensive alternative splicing to generate CD44s (CD44 standard) and CD44v (CD44 variants) [4-6]. CD44s consists of exons $1-5$ and 16-20 and is called the constant form. The variable exons are typically numbered v1-v10 (v1 is not encoded in humans), corresponding to the genomic exons $6-15$, and are alternatively spliced and incorporated into the variable region either singly or in combination. This process has the potential to generate thousands of different CD44 isoforms (Additional file 1: Figure S1) [6-8], and as a result, CD44 has complex and diverse functions.

CD44 was initially identified as a lymphocyte homing receptor and transmembrane glycoprotein [4,9] commonly expressed in embryonic stem cells [10] and in

\section{Biomed Central}

(c) 2014 Li et al.; licensee BioMed Central Ltd. This is an Open Access article distributed under the terms of the Creative Commons Attribution License (http://creativecommons.org/licenses/by/2.0), which permits unrestricted use, distribution, and reproduction in any medium, provided the original work is properly credited. The Creative Commons Public Domain Dedication waiver (http://creativecommons.org/publicdomain/zero/1.0/) applies to the data made available in this article, unless otherwise stated. 
hematopoietic and cancer stem cells [11-13]. Although CD44 plays an important role in many cell processes, including growth, differentiation and motility [14], there are discrepancies in the literature about the roles of CD44v and CD44s in tumor progression. In certain cancers, CD44s and CD44v are considered to be tumor progression promoters [15-27], but in other cancers, CD44s and $C D 44 v$ may be involved in tumor suppression [28-39]. These discrepancies may be the result of different methods for detecting CD44 (such as immunohistochemistry (IHC) or PCR) and identifying different CD44 variants in different tumor types. The roles of CD44 in $\mathrm{PCa}$ are still disputed. Tsukuda, $\mathrm{H}$ [40] reported that CD44v6 and CD44v2 were expressed in the pancreatic juice of patients with pancreatic carcinoma, but the authors also reported CD44v expression in normal cases. Rall, C. J. [41] studied CD44 expression in 21 clinical PCa tissues and reported the expression of CD44v6, CD44v8-9, CD44v8-10 and CD44s, although only CD44v6 may be involved in tumor metastasis. Tomaszewska, $\mathrm{R}$ [42] reported that CD44v6 and CD44s expression was positive in pancreatic carcinoma, and Gotoda, T. et al. [43] reported that CD44v6 and CD44v2 may be useful markers for poor survival after studying the expression of CD44v6, CD44v2 and CD44s via IHC. However, all studies found no significant association between CD44s and tumor progression.

In fact, the expression patterns of CD44 in pancreatic carcinoma have not been systematically investigated at the mRNA level. To investigate whether CD44 expression patterns are related to pancreatic carcinoma metastasis and prognosis, we designed a primer specific for each CD44 variant (CD44v2-CD44v10 and CD44s), detected the expression patterns of CD44 in 101 clinical pancreatic carcinoma samples, and analyzed the relationship of those patterns with the clinical characteristics of pancreatic carcinoma.

\section{Methods}

\section{Patients and specimens}

A total of 101 patients underwent surgery for pancreatic carcinoma at the Department of Hepatobiliary Surgery Institute, Southwest Hospital, Third Military Medical University, China, from January 2008 to January 2010. All patients underwent curative resection by pancreaticoduodenectomy or pylorus-preserving pancreaticoduodenectomy with lymph node dissection. None of the patients received neoadjuvant or adjuvant radio/chemotherapy. All 101 tumor samples were cryopreserved in liquid nitrogen at the time of excision to facilitate RNA extraction and quantitative real-time PCR (qRT-PCR) analysis. The patient characteristics are shown in Table 1. All patients were followed up by radiography, ultrasonography and computed tomography every 3 months after discharge. The median follow-up period was 12 months (range 4-46 months), and during this period, 10 patients were found to have liver metastases, and 1 patient was found to have lung metastases.

This study was approved by the Ethics Committee of Southwest Hospital, and all patients provided written informed consent.

\section{Cell culture}

The Aspc-1, Cfpac-1 and Panc-1 pancreatic carcinoma cell lines were purchased from the Shanghai Biomedical Institute. The Cfpac-1 and Panc- 1 cell lines were maintained in Dulbecco's Modified Eagle's Medium (DMEM; HyClone, Thermo, USA), and the Aspc-1 cell line was maintained in Roswell Park Memorial Institute 1640 medium (1640; HyClone, Thermo, USA). All cell cultures were supplemented with $10 \%$ fetal bovine serum (FBS; GIBCO/Invitrogen, CA, USA) in the presence of $100 \mathrm{U} /$ $\mathrm{ml}$ penicillin and $100 \mathrm{mg} / \mathrm{ml}$ streptomycin. All cell lines were cultured at $37^{\circ} \mathrm{C}$ in a humidified atmosphere containing $5 \% \mathrm{CO}_{2}$.

\section{Cell invasion assay}

To perform invasion assays, $5 \times 10^{5}$ cells in $300 \mu \mathrm{L}$ serumfree medium were placed in the upper chamber (Millipore, MA, USA) of an insert coated with $30 \mu \mathrm{L}$ Matrigel (BD, Franklin Lakes, USA), and $600 \mu \mathrm{L}$ medium (DMEM or 1640) containing $10 \%$ FBS was added to the lower chamber. After a 24-hour incubation, the cells remaining on the upper membrane were removed with cotton wool. The cells that had passed through the membrane were stained with hematoxylin, imaged using a BX41 microscope (Olympus, Tokyo, Japan) and counted in 10 fields per well at 200x magnification using a CKX41 inverted microscope (Olympus, Tokyo, Japan). The experiments were independently repeated three times.

\section{RNA extraction and quantitative real-time PCR}

Total RNA was extracted from tissues or cultured cells using RNAiso Plus reagent (TaKaRa, Dalian, China) according to the manufacturer's protocol. The RNA was stored at $-80^{\circ} \mathrm{C}$, and reverse transcription (RT) of the extracted RNA was performed using the PrimeScript RT reagent Kit with gDNA Eraser (TaKaRa, Dalian, China). The cDNA was stored at $-20^{\circ} \mathrm{C}$. qRT-PCR assays were performed to detect CD44 expression using the PrimeScript RT reagent Kit and SYBR Premix Ex Taq (TaKaRa, Dalian, China) according to the manufacturer's instructions. The results were normalized to the expression of beta-actin. The primers used are shown in Additional file 2: Table S1. For quantitative measurement of the CD44 variable exons expressed, qRT-PCR was performed using a CFX96 Real-Time system (Bio-Rad, CA, USA) with the following cycling conditions: $95^{\circ} \mathrm{C}$ for 30 sec, followed by 40 cycles of $95^{\circ} \mathrm{C}$ for $5 \mathrm{sec}$ and $60^{\circ} \mathrm{C}$ for 
Table 1 Associations between the status of CD44 variants and CD44s and the categorical clinicopathological parameters of pancreatic carcinoma ( $\mathrm{n}=101$ )

\begin{tabular}{|c|c|c|c|c|c|c|c|c|c|c|c|c|c|c|c|c|c|c|c|c|}
\hline \multirow[t]{2}{*}{ Parameters } & \multicolumn{2}{|c|}{ CD44v2 } & \multicolumn{2}{|c|}{ CD44v3 } & \multicolumn{2}{|c|}{ CD44v4 } & \multicolumn{2}{|c|}{ CD44v5 } & \multicolumn{2}{|c|}{ CD44v6 } & \multicolumn{2}{|c|}{ CD44v7 } & \multicolumn{2}{|c|}{ CD44v8 } & \multicolumn{2}{|c|}{ CD44v9 } & \multicolumn{2}{|c|}{ CD44v10 } & \multicolumn{2}{|c|}{ CD44s } \\
\hline & + & - & + & - & + & - & + & - & + & - & + & - & + & - & + & - & + & - & + & - \\
\hline \multicolumn{21}{|l|}{ Gender } \\
\hline P-value & \multicolumn{2}{|c|}{0.379} & \multicolumn{2}{|c|}{0.379} & \multicolumn{2}{|c|}{0.956} & \multicolumn{2}{|c|}{0.68} & \multicolumn{2}{|c|}{0.956} & \multicolumn{2}{|c|}{0.178} & \multicolumn{2}{|c|}{0.956} & \multicolumn{2}{|c|}{0.956} & \multicolumn{2}{|c|}{0.322} & \multicolumn{2}{|c|}{0.379} \\
\hline Male/Female & $40 / 10$ & $37 / 14$ & $40 / 10$ & $37 / 14$ & $39 / 12$ & $38 / 12$ & $39 / 11$ & $38 / 13$ & $39 / 12$ & $38 / 12$ & $41 / 9$ & $36 / 15$ & $38 / 12$ & $39 / 12$ & $39 / 12$ & $38 / 12$ & $41 / 10$ & $36 / 14$ & $40 / 10$ & $37 / 14$ \\
\hline Age, years & & & & & & & & & & & & & & & & & & & & \\
\hline P-value & & & & & 0.551 & & & 77 & & & & & & & & & & & & \\
\hline$<65 / \geq 65$ & $36 / 14$ & $36 / 15$ & $37 / 13$ & $35 / 16$ & $37 / 13$ & $35 / 16$ & $35 / 15$ & $37 / 14$ & $37 / 14$ & $35 / 15$ & $37 / 13$ & $35 / 16$ & $37 / 13$ & $35 / 16$ & $37 / 14$ & $35 / 15$ & $38 / 13$ & $34 / 16$ & $37 / 13$ & $35 / 16$ \\
\hline Tumor location & & & & & & & & & & & & & & & & & & & & \\
\hline P-value & & & & & 0.7 & & & 37 & & & & & & & & & & & & 53 \\
\hline Head/Body,tail & $42 / 8$ & $46 / 5$ & $44 / 6$ & $44 / 7$ & $45 / 6$ & $43 / 7$ & $43 / 7$ & $45 / 6$ & $44 / 7$ & $44 / 6$ & $44 / 6$ & $44 / 7$ & $44 / 6$ & $44 / 7$ & $45 / 6$ & $43 / 7$ & $45 / 6$ & $43 / 7$ & $42 / 8$ & $46 / 5$ \\
\hline Tumor size, cm & & & & & & & & & & & & & & & & & & & & \\
\hline P-value & & & & & 0.4 & & & 46 & & & & & & & & & & & & \\
\hline$\leq 2 />2$ & $19 / 31$ & $20 / 31$ & $18 / 32$ & $21 / 30$ & $18 / 33$ & $21 / 29$ & $17 / 33$ & $22 / 29$ & $18 / 33$ & $21 / 29$ & $19 / 31$ & $20 / 31$ & $19 / 31$ & $20 / 31$ & $20 / 31$ & 19/31 & $21 / 30$ & $18 / 32$ & $22 / 28$ & $17 / 3$ \\
\hline Lymphatic invas & & & & & & & & & & & & & & & & & & & & \\
\hline P-value & & & & & 0.0 & & & 97 & & & & & & & & & & & & 74 \\
\hline Neg/Pos & $27 / 23$ & $30 / 21$ & $25 / 25$ & $32 / 19$ & $24 / 27$ & $33 / 17$ & $25 / 25$ & $32 / 19$ & $23 / 28$ & $34 / 16$ & $24 / 26$ & $33 / 18$ & $24 / 26$ & $33 / 18$ & $23 / 28$ & $34 / 16$ & $25 / 26$ & $32 / 18$ & $30 / 20$ & $27 / 24$ \\
\hline Vascular invasior & & & & & & & & & & & & & & & & & & & & \\
\hline P-value & & & & & 0.4 & & & & & & & & & & & & & & & 03 \\
\hline Neg/Pos & $30 / 20$ & $43 / 8$ & $38 / 12$ & $35 / 16$ & $35 / 16$ & $38 / 12$ & $37 / 13$ & $36 / 15$ & $37 / 14$ & $36 / 14$ & $38 / 12$ & $35 / 16$ & $36 / 14$ & $37 / 14$ & $36 / 15$ & $37 / 13$ & $37 / 14$ & $36 / 14$ & $39 / 11$ & $34 / 17$ \\
\hline Neural invasion & & & & & & & & & & & & & & & & & & & & \\
\hline P-value & & & & & 0.7 & & & & & & & & & & & & & & & \\
\hline Neg/Pos & $36 / 14$ & $36 / 15$ & $36 / 14$ & $36 / 15$ & $37 / 14$ & $35 / 15$ & $38 / 12$ & $34 / 17$ & $36 / 15$ & $36 / 14$ & $35 / 15$ & $37 / 14$ & $37 / 13$ & $35 / 16$ & $39 / 12$ & $33 / 17$ & $36 / 15$ & $36 / 14$ & $34 / 16$ & $38 / 13$ \\
\hline Duodenal invasic & & & & & & & & & & & & & & & & & & & & \\
\hline P-value & & & & & 0.6 & & & & & & & & & & & & & & & \\
\hline Neg/Pos & $38 / 12$ & $43 / 8$ & $39 / 11$ & $42 / 9$ & $40 / 11$ & $41 / 9$ & $41 / 9$ & $40 / 11$ & $43 / 8$ & $38 / 12$ & $38 / 12$ & $43 / 8$ & $41 / 9$ & $40 / 11$ & $42 / 9$ & $39 / 11$ & $41 / 10$ & $40 / 10$ & $43 / 7$ & $38 / 13$ \\
\hline Hepatic metas & & & & & & & & & & & & & & & & & & & & \\
\hline P-value & & & & & 0.0 & & & & & & & & & & & & & & & \\
\hline Neg/Pos & $44 / 6$ & $47 / 4$ & $42 / 8$ & $49 / 2$ & $43 / 8$ & $48 / 2$ & $43 / 7$ & $48 / 3$ & $43 / 8$ & $48 / 2$ & $43 / 7$ & $48 / 3$ & $42 / 8$ & $49 / 2$ & $43 / 8$ & $48 / 2$ & $43 / 8$ & $48 / 2$ & $48 / 2$ & $43 / 8$ \\
\hline Differentiation & & & & & & & & & & & & & & & & & & & & \\
\hline P-value & & & & & 0.5 & & & 24 & & & & & & & & & & & & \\
\hline Poor & 13 & 16 & 18 & 11 & 17 & 12 & 19 & 10 & 15 & 14 & 14 & 15 & 15 & 14 & 13 & 16 & 16 & 13 & 11 & 18 \\
\hline Middle & 32 & 31 & 26 & 37 & 29 & 34 & 27 & 36 & 29 & 34 & 31 & 32 & 29 & 34 & 32 & 31 & 29 & 34 & 31 & 32 \\
\hline Well & 5 & 4 & 6 & 3 & 5 & 4 & 4 & 5 & 7 & 2 & 5 & 4 & 6 & 3 & 6 & 4 & 6 & 3 & 8 & 1 \\
\hline
\end{tabular}


Table 1 Associations between the status of CD44 variants and CD44s and the categorical clinicopathological parameters of pancreatic carcinoma ( $=101$ ) (Continued)

\begin{tabular}{|c|c|c|c|c|c|c|c|c|c|c|c|c|c|c|c|c|c|c|c|c|}
\hline \multicolumn{21}{|c|}{ Stage (UICC) } \\
\hline P-value & \multicolumn{2}{|c|}{0.837} & \multicolumn{2}{|c|}{0.109} & \multicolumn{2}{|c|}{0.057} & \multicolumn{2}{|c|}{0.135} & \multicolumn{2}{|c|}{0.008} & \multicolumn{2}{|c|}{0.286} & \multicolumn{2}{|c|}{0.061} & \multicolumn{2}{|c|}{0.027} & \multicolumn{2}{|c|}{0.143} & \multicolumn{2}{|c|}{0.028} \\
\hline $\mid \mathrm{A} / \mathrm{B}$ & $4 / 11$ & $6 / 14$ & $3 / 13$ & $7 / 12$ & $2 / 12$ & $8 / 13$ & $2 / 13$ & $8 / 12$ & $2 / 13$ & $8 / 12$ & $3 / 12$ & $7 / 13$ & $4 / 12$ & $6 / 13$ & $4 / 11$ & $6 / 14$ & $4 / 12$ & $6 / 13$ & $6 / 18$ & $4 / 7$ \\
\hline$\|\mathrm{A} /\| \mathrm{B}$ & $9 / 20$ & $6 / 20$ & $4 / 22$ & $11 / 18$ & $5 / 24$ & $10 / 16$ & $5 / 23$ & $10 / 17$ & $3 / 25$ & $12 / 15$ & $5 / 23$ & $10 / 17$ & $3 / 23$ & $12 / 17$ & $3 / 25$ & $12 / 15$ & $4 / 23$ & $11 / 17$ & $4 / 19$ & $11 / 21$ \\
\hline III/IV & 0/6 & $0 / 5$ & 0/8 & $0 / 3$ & $0 / 8$ & $0 / 3$ & 0/7 & $0 / 4$ & $0 / 8$ & $0 / 3$ & $0 / 7$ & $0 / 4$ & $0 / 8$ & $0 / 3$ & $0 / 8$ & $0 / 3$ & $0 / 8$ & $0 / 3$ & $0 / 3$ & $0 / 8$ \\
\hline
\end{tabular}

The bold values indicate P-values less than 0.05 , Neg (-): negative, Pos(+): positive, UICC Union for International Cancer Control. 
30 sec. The qRT-PCR results were analyzed and expressed relative to those of a normal pancreas sample and were then converted to fold changes. The PCR products were separated on a $2.0 \%$ agarose gel, stained with ethidium bromide (EB) and photographed with a video camera (Vilber Lourmat, Marne-la-Vallée, France). The sizes of all of the qRT-PCR products for CD44v and CD44s are referred to in Additional file 2: Table S1. All experiments were performed in triplicate, and the means of three values are presented.

\section{Calculating the optimized cut-off point for CD44v2- CD44v10 and CD44s}

As quantitative analysis of CD44v2-CD44v10 and CD44s expression in pancreatic carcinoma is novel, no established cut-off points are available. For this analysis, we used two methods to select the cut-off point: (1) the logrank test, performed by testing the prognostic value at each possible cut-off point (e.g., 25\%, 50\%, 75\%) and (2) Cox regression analysis, including all possible cut-off points (e.g., 25\%, 50\%, 75\%). We divided the samples into two groups, according to the median and the 25th and 75th percentiles. We found that the median cut-off point gave a lower $\mathrm{P}$-value than did the other points using both the log-rank test and Cox regression analysis, with a comparable hazard ratio (HR) for overall survival (OS). Only CD44v6, CD44v9 and CD44s were significantly associated with OS (data not shown), and only those variants were used in the cut-off point analysis (Additional file 3: Figure S2). Using the median cut-off point, we defined a group with 'low CD44' (negative) and a group with 'high CD44' (positive). All Chi-square $\left(\chi^{2}\right)$ analysis, Kaplan-Meier (KM) survival analysis and Cox regression analysis were performed using data based on the median cut-off point.

\section{Statistical analysis}

All analyses were performed using SPSS 19.0 software (IBM, Chicago, USA). The correlation between categorical variables was evaluated using the $X^{2}$ test. Data were analyzed using Student's t-test if the involved comparison groups followed normal distributions; otherwise, the nonparametric Mann-Whitney test was applied. Univariate analysis was conducted by the KM method (the log-rank test). Multivariate analysis was performed using the stepwise Cox multivariate proportional hazard regression model (forward, likelihood ratio), and the values of variables not in the equation were picked from step 1 . P-values $<0.05$ were considered to be statistically significant, and all statistical analysis was completed under the guidance of experienced experts from the Statistics Department of third military medical university.

\section{Results}

Increased expression of CD44v and decreased expression of CD44s were associated with the invasion and metastatic potential of $\mathrm{PCa}$

To analyze the expression levels of all CD44 variants, we first designed primers for each variant. Due to the complexity of CD44 isoform expression, we hoped to find a novel method for studying CD44, rather than using previous methods of analyzing CD44 isoforms. The primers for CD44v2-CDv10 were therefore designed to be located in each exon, rather than in exons 1-5 and 16-20, as had been performed previously. The sense primer $\left(3^{\prime}\right)$ for CD44s was located in exon 5 , and the antisense primer $\left(5^{\prime}\right)$ spanned exons 5 through 16 , producing only CD44s, as described by Konig, $\mathrm{H}$ [44] (Additional file 1: Figure S1, Additional file 2: Table S1). All products were verified by agarose electrophoresis (Figure 1B).

We then detected the expression levels of all CD44 variants in the three pancreatic carcinoma cell lines. Among the Aspc-1 (As), Cfpac-1 (Cf) and Panc-1 (Pa) pancreatic carcinoma cell lines, the expression levels of CD44v2-CD44v10 (CD44v), from highest to lowest, were in $\mathrm{As}, \mathrm{Cf}$ and $\mathrm{Pa}$. Interestingly, the expression levels of CD44s, from highest to lowest, were in $\mathrm{Pa}, \mathrm{Cf}$ and As (Figure 2C, D), which indicates that the pancreatic carcinoma cell lines expressed different levels of CD44v and CD44s.

We next tested the cell invasion capabilities of these three pancreatic carcinoma cell lines using transwell assays. The As cell line showed the highest invasion capacity; $\mathrm{Cf}$, the median invasion capacity; and $\mathrm{Pa}$, the lowest invasion capacity (Figure 2A, B). These results suggest that increased expression of $\mathrm{CD} 44 \mathrm{v}$ or decreased expression of $\mathrm{CD} 44 \mathrm{~s}$ is associated with the invasion potential of the PCa cell lines.

To further explore the relationship between the expression of CD44 and PCa metastasis, we analyzed the expression levels of $\mathrm{CD} 44 \mathrm{v}$ and CD44s in five metastatic pancreatic carcinoma samples (which included two hepatic metastases, two lymphatic invasions and one vascular invasion), five non-metastatic samples and ten peritumoral tissue samples. As shown in Figure 1A, when compared with peritumoral tissue, PCa showed both increased CD44v expression and decreased CD44s expression (CD44v5, v6, v9 and v10 and CD44s showed significant differences). Moreover, higher expression of CD44v and lower expression of CD44s were found in metastatic samples compared with non-metastatic samples (CD44v6 and CD44s showed significant differences). These results are consistent with the observations noted when analyzing the three cell lines, which suggests that the expression of CD44v and CD44s is associated with tumor metastasis. 

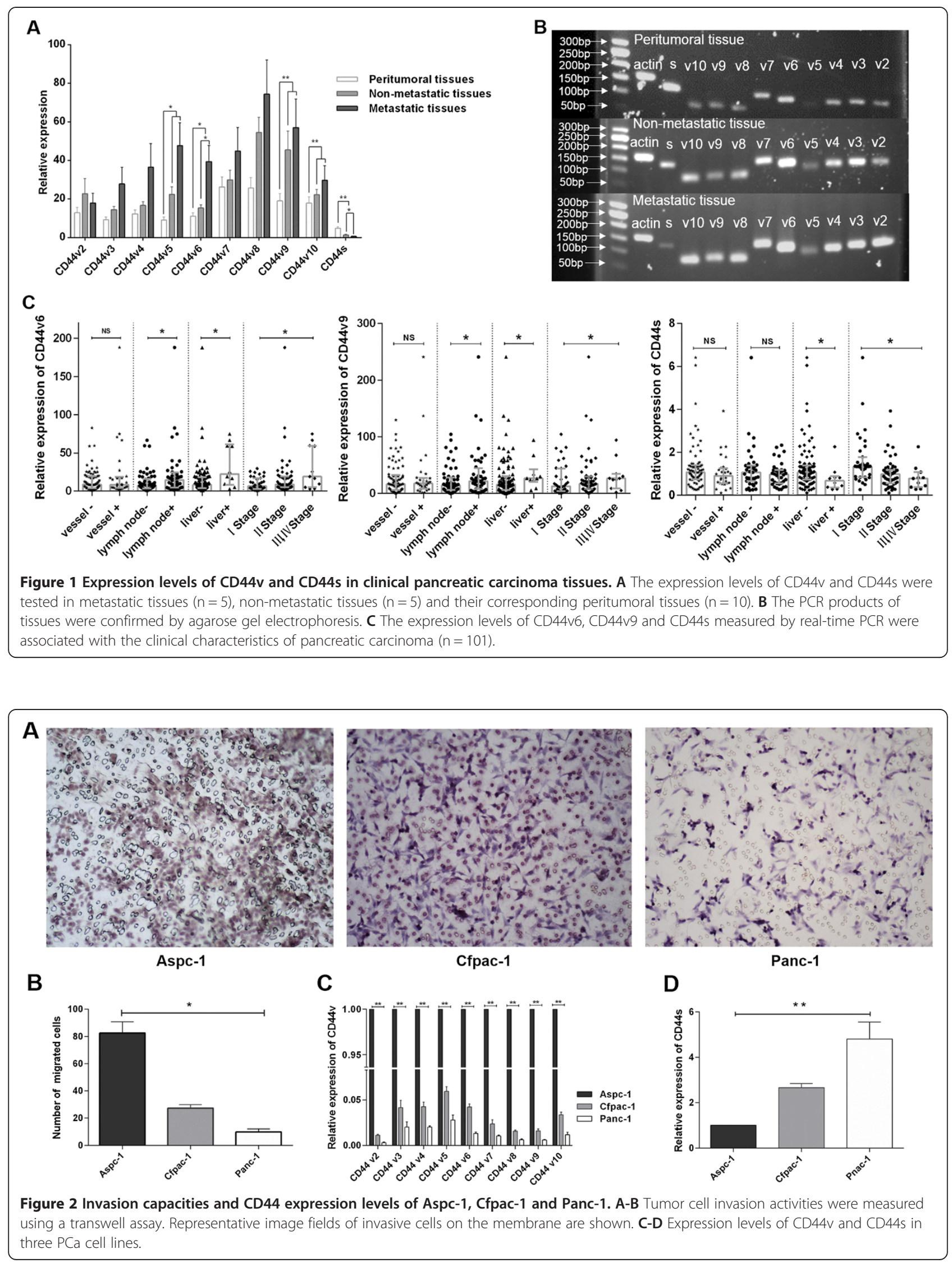
$\mathrm{CD}_{4} 4 \mathrm{v6}^{+}, \mathrm{CD} 44 \mathrm{v} 9^{+}$and $\mathrm{CD} 44 \mathrm{~s}^{-}$may be associated with poor prognosis in pancreatic carcinoma

To further investigate whether CD44v2-CD44v10 and $\mathrm{CD} 44 \mathrm{~s}$ are involved pancreatic carcinoma metastasis, we analyzed the relationship between the clinical characteristics of pancreatic carcinoma patients and the expression of CD44v2-CD44v10 and CD44s. As shown in Table $1, \mathrm{CD}_{4} 4 \mathrm{v}^{+}$and $\mathrm{CD} 44 \mathrm{v}^{+}$were significantly correlated with lymph node metastasis $(P=0.02)$, liver metastasis $(\mathrm{P}=0.049)$ and TNM stage $(\mathrm{P}=0.008$ and $\mathrm{P}=0.027$, respectively), and $C D 44 \mathrm{~s}^{-}$was significantly correlated with liver metastasis $(P=0.049)$, differentiation $(\mathrm{P}=0.028)$ and TNM stage $(\mathrm{P}=0.028)$. However, $\mathrm{CD} 44 \mathrm{v} 2-\mathrm{CD} 44 \mathrm{v} 5^{+}, \mathrm{CD} 44 \mathrm{v}^{+}, \mathrm{CD} 44 \mathrm{v} 8^{+}$and $\mathrm{CD} 44 \mathrm{v} 10^{+}$ were not correlated with any clinicopathological characteristics of pancreatic carcinoma. We further applied a nonparametric Mann-Whitney test to analyze the relationships between the clinicopathological characteristics and the expression of CD44v6, CD44v9 and CD44s. As shown in Figure 1C, CD44v6 $6^{+}$and CD44v9 ${ }^{+}$ were correlated with lymph node metastasis, liver metastasis and TNM stage, and CD44s ${ }^{-}$was associated with liver metastasis and TNM stage. These results indicate that $\mathrm{CD}_{4} 4 \mathrm{v}^{+}, \mathrm{CD} 44 \mathrm{v} 9^{+}$and $\mathrm{CD} 44 \mathrm{~s}^{-}$may be associated with poor prognosis in pancreatic carcinoma patients.
$\mathrm{CD}_{446^{+}}, \mathrm{CD} 44 \mathrm{v} 9^{+}$and $\mathrm{CD} 44 \mathrm{~s}^{-}$are key factors that affect the survival of pancreatic carcinoma patients

We further analyzed whether the expression levels of CD44v2-CD44v10 and CD44s were associated with the survival rate of patients with pancreatic carcinoma. KM curve analysis showed that patients with $\mathrm{CD} 44 \mathrm{v}^{+}$and $\mathrm{CD} 44 \mathrm{v} 9^{+}$had significantly low survival rates $(\mathrm{P}=0.01$ and $\mathrm{P}=0.047$, respectively). In contrast, patients with $\mathrm{CD} 44 \mathrm{~s}^{-}$had significantly low survival rates $(\mathrm{P}=0.032)$ (Figure 3A-C). Patients with CD44v2-CD44v5 ${ }^{+}, \mathrm{CD} 44 \mathrm{v} 7^{+}$, $\mathrm{CD} 44 \mathrm{v}^{+}$and $\mathrm{CD} 44 \mathrm{v} 10^{+}$demonstrated no differences in survival rate (data not shown). Interestingly, pancreatic carcinoma patients with tumors that were $\mathrm{CD} 44 \mathrm{v}^{+} / \mathrm{CD} 44 \mathrm{~s}^{-}$ or $\mathrm{CD} 44 \mathrm{v} 9^{+} / \mathrm{CD} 44 \mathrm{~s}^{-}$had a significantly lower survival rate than did patients with tumors expressing $\mathrm{CD} 44 \mathrm{v} 6^{+}$, $\mathrm{CD} 44 \mathrm{v} 9^{+}$or $\mathrm{CD} 44 \mathrm{~s}^{-}$alone. However, CD44v6 ${ }^{+} / \mathrm{CD} 44 \mathrm{v} 9^{+}$ did not further decrease the patients' survival rate (Figure 3D-F). These results suggest that $\mathrm{CD} 44 \mathrm{v} 6^{+}$, $\mathrm{CD} 44 \mathrm{v}^{+}$and $\mathrm{CD} 44 \mathrm{~s}^{-}$are key factors affecting the survival of pancreatic carcinoma patients.

\section{$\mathrm{CD}_{44} \mathrm{v}^{+} / \mathrm{CD} 44 \mathrm{~s}^{-}$expression was an independent risk factor associated with the OS rate of pancreatic carcinoma patients}

We used univariate and multivariate analyses to identify independent risk factors associated with the survival rate
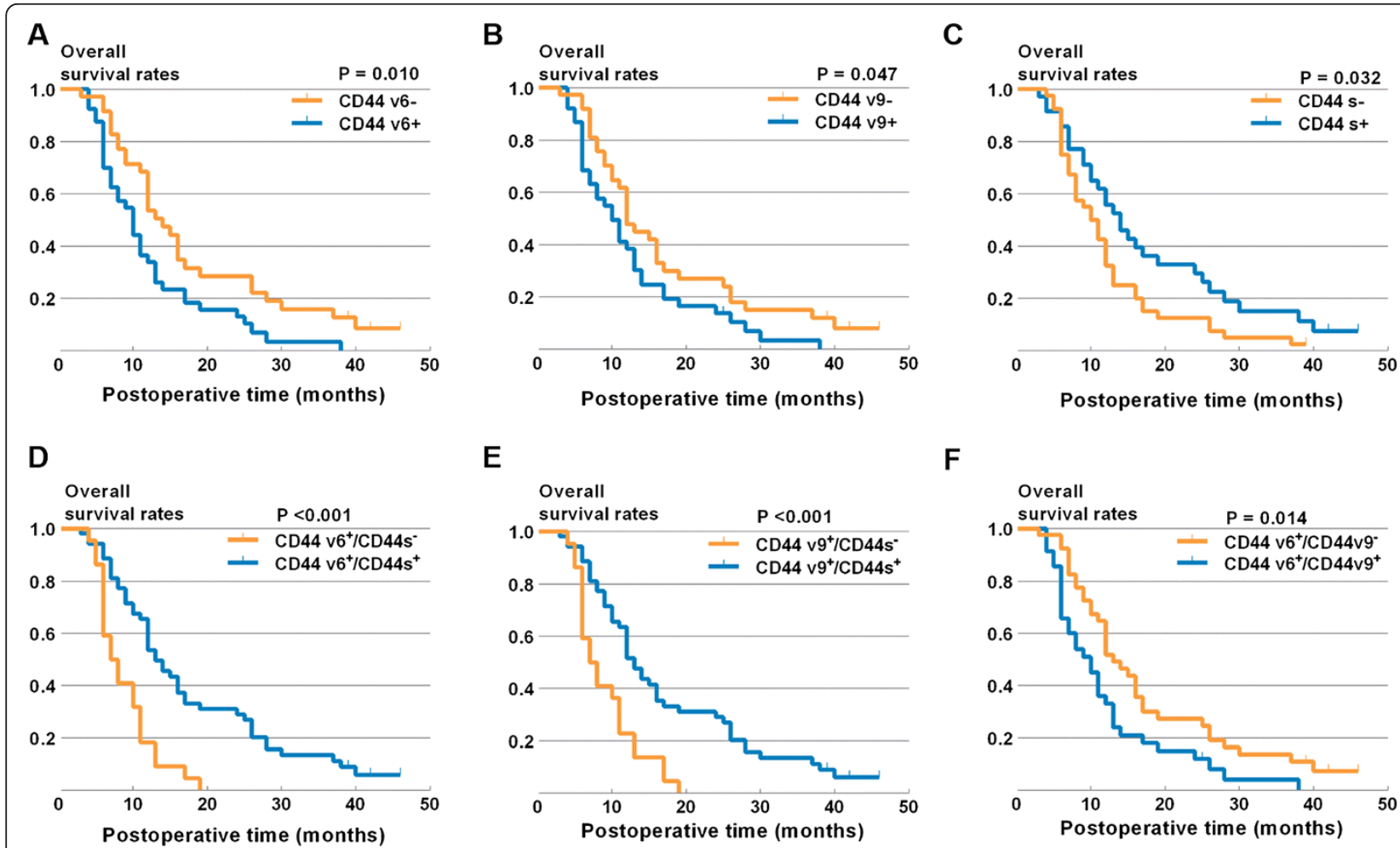

Figure $3 \mathrm{KM}$ survival curves for the OS of patients with pancreatic carcinoma according to CD44v6 (A), CD44v9 (B), CD44s (C), CD44v6/ CD44s (D), CD44v9/CD44s (E) and CD44v6/CD44v9 (F). 
Table 2 Univariate analysis of prognostic factors in pancreatic adenocarcinoma $(n=101)$

\begin{tabular}{lcccc}
\hline Variables & $\mathbf{n}$ & $\begin{array}{c}\text { Median survival } \\
\text { time (months) }\end{array}$ & $\begin{array}{c}\text { 2-year survival } \\
\text { rate (\%) }\end{array}$ & P-value \\
\hline Age (years) & & & & 0.545 \\
$\quad<65$ & 53 & 12 & 20.0 & \\
$\quad \geq 65$ & 22 & 13 & 20.2 & \\
Gender & & & & 0.793
\end{tabular}

$\begin{array}{llll}\text { Female } & 16 & 10 & 12.5 \\ \text { Male } & 59 & 12 & 22.5\end{array}$

Tumor size $(\mathrm{cm})$

$\leq 2$

$>2$

$\mathrm{pN}$

Negative

Positive

PV

Negative

Positive

Hepatic metastases

Negative

Positive

Differentiation

Poor

Moderate

Well

pStage (UICC)

I

॥

III,IV

CD44v6 expression

Negative

Positive

CD44v9 expression

Negative

Positive

CD44s expression

Negative

Positive

CD44v6,v9 expression

Negative

Positive

28

12

11

47

39

14

10

36

12

10

CD44v6,s expression

Negative

Positive
2.5
0.000
Table 2 Univariate analysis of prognostic factors in pancreatic adenocarcinoma $(\mathbf{n}=\mathbf{1 0 1})$ (Continued)

\begin{tabular}{lcccc}
\hline CD 44v9,s expression & & & & $\mathbf{0 . 0 0 0}$ \\
Negative & 53 & 13 & 29.0 & \\
Positive & 22 & 7 & 0 & \\
\hline
\end{tabular}

The bold values indicate $\mathrm{P}$-values less than 0.05. $p N$ pathological node stage, $p V$ pathological vessel status, $p$ Stage TNM stage (UICC), s CD44s.

of pancreatic carcinoma patients. As shown in Tables 2 and 3, univariate analysis revealed that lymph node metastasis (pN); vessel invasion (pV); hepatic metastases; TNM stage; and individual or co-expression of CD44v6 $6^{+}$, $\mathrm{CD} 44 \mathrm{v} 9^{+}$and $\mathrm{CD} 44 \mathrm{~s}^{-}$were risk factors that significantly affected the survival of pancreatic carcinoma patients. However, multivariate analysis showed that only $\mathrm{D} 44 \mathrm{v}^{+} / \mathrm{CD} 44 \mathrm{~s}^{-}$ and $\mathrm{pN}$ were independent risk factors affecting the OS of pancreatic carcinoma patients $(\mathrm{P}=0.003$ and $\mathrm{P}=0.002$, respectively). Therefore, among all $\mathrm{CD} 44$ variants, $\mathrm{CD} 44 \mathrm{v6}^{+} / \mathrm{CD} 44 \mathrm{~s}^{-}$was an independent risk factor affecting the OS rate of pancreatic carcinoma patients.

\section{Discussion}

CD44 has been studied for three decades, with hundreds of papers devoted to cancer research, but no consensus opinion on cancer progression has been reached until now. Thousands of CD44 isoforms can be generated due to alternative splicing, and each isoform may function differently. Traditional methods for studying CD44 at the mRNA level make it too difficult to distinguish between splicing isoforms and to analyze clinical tissues. In the present study, we designed primers specific for each exon of CD44 variants and for the exons of CD44s. We could therefore effectively distinguish each CD44 variant in pancreatic carcinoma tissue, rather than trying to identify thousands of complicated CD44 isoforms. A similar method was also applied in Slominski's research [45]. Although the CD44 variants were distinguished only at mRNA level and protein-level validation of these data is required, but there are no enough specific antibodies to recognize each $\mathrm{CD} 44$ variant at present. Therefore, this method is also effective and useful for identifying CD44 splicing isoforms.

Many factors such as lymphatic vascular density, vascular endothelial growth factors (VEGF) and CD44 are involved in $\mathrm{PCa}$ progression [46-48]. Our results suggest that increased expression of CD44v and decreased expression of CD44s are associated with pancreatic carcinoma metastasis and progression. First, we found that CD44v expression was increased and that CD44s expression was decreased in pancreatic carcinoma cell lines and in human tissue samples. Second, the individual expression of CD44v and CD44s was associated with invasion and metastasis in pancreatic carcinoma cell 
Table 3 Multivariate analysis of the prognostic factors associated with survival in pancreatic adenocarcinoma $(n=101)$

\begin{tabular}{|c|c|c|c|c|}
\hline Independent factors & Univariate $\mathrm{P}$ & Multivariate $\mathbf{P}$ & Hazard ratio & 95\% Confidence interval \\
\hline $\mathrm{Pn}$ (Neg/Pos) & 0.002 & 0.002 & 2.313 & $1.376-3.889$ \\
\hline pv (Neg/Pos) & 0.045 & 0.370 & 1.342 & $0.705-2.557$ \\
\hline Hepatic metastases (Neg/Pos) & 0.000 & 0.051 & 2.558 & $0.998-6.555$ \\
\hline pStage $(I / I / I I I, \mid \mathrm{V})$ & 0.000 & 0.925 & 1.041 & $0.450-2.407$ \\
\hline CD44v6 expression (Neg/Pos) & 0.010 & 0.281 & 1.869 & $0.600-5.824$ \\
\hline CD44v9 expression (Neg/Pos) & 0.047 & 0.718 & 0.748 & $0.155-3.603$ \\
\hline CD44s expression (Neg/Pos) & 0.032 & 1.000 & 1.000 & $0.437-2.287$ \\
\hline CD44v6,v9 expression (Neg/Pos) & 0.014 & 0.809 & 0.809 & $0.146-4.486$ \\
\hline CD44v6,s expression (Neg/Pos) & 0.000 & 0.003 & 2.602 & $1.390-4.870$ \\
\hline CD44v9,s expression (Neg/Pos) & 0.000 & 0.810 & 0.808 & $0.142-4.587$ \\
\hline
\end{tabular}

The bold values indicate P-values less than 0.05 in multivariate analysis, $p N$ pathological node stage, $p V$ pathological vessel status, $p S t a g e$ TNM stage (UICC), $s \mathrm{CD} 44 \mathrm{~s}$, Neg negative, Pos positive.

lines and in resected PCa tissue. Our results indicate that $\mathrm{CD} 44 \mathrm{v}$ and $\mathrm{CD} 44 \mathrm{~s}$ may play different roles in pancreatic carcinoma metastasis. These results are consistent with the findings of previous studies, which suggested that $\mathrm{CD} 44 \mathrm{v}$ and CD44s function differently in pancreatic carcinoma than in other cancers $[41,43,49]$.

CD44v6 and CD44v9 have been identified as markers for tumor progression and metastasis in various cancers [50-53]. However, no consensus has been reached regarding the role of CD44s. The results of the present study indicate that $\mathrm{CD} 44 \mathrm{v} 6^{+}, \mathrm{CD} 44 \mathrm{v} 9^{+}$and $\mathrm{CD} 44 \mathrm{~s}^{-}$may affect the prognosis of pancreatic carcinoma. CD44 $6^{+}$ and $\mathrm{CD} 44 \mathrm{v} 9^{+}$were significantly correlated with lymph node invasion, liver metastasis and TNM stage, and CD44s- was correlated with liver metastasis, tumor differentiation and TNM stage. CD44v2-CD44v5 $5^{+}, \mathrm{CD} 44 \mathrm{v} 7^{+}$, $\mathrm{CD} 44 \mathrm{v}^{+}$and $\mathrm{CD} 44 \mathrm{v} 10^{+}$were not correlated with any clinicopathological characteristics of pancreatic carcinoma. A nonparametric test showed similar results. Therefore, in pancreatic carcinoma, CD44v6 ${ }^{+}, \mathrm{CD} 44 \mathrm{v} 9^{+}$and $\mathrm{CD} 44 \mathrm{~s}^{-}$ may be related to poor prognosis.

CD44 is a novel type of molecule that may be involved in tumor growth, invasion and metastasis. A recent study showed that the switch of CD44s to CD44v6 can promote the development of a normal mammary gland into carcinoma [54]. Furthermore, it has been shown that CD44v6 and CD44v9 can increase invasion and metastasis via cooperating with c-Met to activate the MEK and Erk signaling pathways [55] and can increase antiapoptotic ability via inhibiting Fas signaling [56]. In the present study, we found that $\mathrm{CD} 44 \mathrm{v} 6^{+}, \mathrm{CD} 44 \mathrm{v} 9^{+}$and CD $44 \mathrm{~s}^{-}$significantly decreased the survival rate of pancreatic carcinoma patients. Additionally, patients with $\mathrm{PCa}$ and co-expression of CD44v6 and CD44s or coexpression of CD44v9 and CD44s had a significantly lower survival rate in comparison with patients with expression of $\mathrm{CD} 44 \mathrm{v} 6^{+}, \mathrm{CD} 44 \mathrm{v} 9^{+}$or $\mathrm{CD} 44 \mathrm{~s}^{-}$alone. Furthermore, $\mathrm{CD} 44 \mathrm{v} 6^{+} / \mathrm{CD} 44 \mathrm{~s}^{-}$was found to be an independent risk factor.

\section{Conclusions}

In this study, we applied a specific method for testing the expression of CD44v2-CD44v10 and CD44s in 101 pancreatic carcinoma tissues, and then further evaluated their roles in pancreatic carcinoma metastasis and prognosis using clinical survival analysis. We demonstrated that among all CD44 variants, CD44v6 $6^{+}, \mathrm{CD} 44 \mathrm{v} 9^{+}$ and $\mathrm{CD} 44 \mathrm{~s}^{-}$were significantly associated with the metastasis and prognosis of pancreatic carcinoma. The different expression patterns of CD44v and CD44s may be useful markers for predicting the prognosis of pancreatic carcinoma.

\section{Additional files}

Additional file 1: Figure S1. Schematic of primers specific for CD44V (A) and CD44s (B) (v2-v10 are abbreviations for CD44V2-CD44v10).

Additional file 2: Table S1. Sequences of the CD44v2-CD44v10, CD44s and beta-actin PCR primers.

Additional file 3: Figure S2. Identification of cut-off points for CD44v6, CD44v9 and CD44s. Population $(n=101)$ was divided into two groups according to the median and the 25th and 75th percentiles. P-values and HRs were calculated (Cox regression) for OS for each cut-off point.

\section{Competing interests}

The authors declare no conflict of interest.

\section{Authors' contributions}

ZHL and XWL designed the study, ZHL and KC carried out the experiments and drafted the manuscript, PJ and XZ participated in the statistical analysis. All authors read and approved the final manuscript.

\section{Acknowledgments}

This work was supported by the Chongqing Natural Science Fund Project (2012JB1032), the Project of the National Natural Science Fund (81272363, 30872497), the National 863 Project of China (No. 2012AA02A201), the 
National Basic Research Program of China (973 Program) (2010CB529400) and the National Science and Technology Major Project of China (2008ZX10002-026). We thank Dr. Yazhou Wu and Dr. Lin Liu (Statistics Department, Military Preventive Medicine, Third Military Medical University) for their statistical assistance.

Received: 17 December 2013 Accepted: 1 April 2014

Published: 8 April 2014

\section{References}

1. Abel EV, Simeone DM: Biology and clinical applications of pancreatic cancer stem cells. Gastroenterology 2013, 144:1241-1248.

2. Wolfgang $\mathrm{CL}$, Herman JM, Laheru DA, Klein AP, Erdek MA, Fishman EK, Hruban RH: Recent progress in pancreatic cancer. CA Cancer J Clin 2013, 63:318-348.

3. Maeda S, Shinchi H, Kurahara H, Mataki Y, Noma H, Maemura K, Aridome K, Yokomine T, Natsugoe S, Aikou T, Takao S: Clinical significance of midkine expression in pancreatic head carcinoma. Br J Cancer 2007, 97:405-411.

4. Goldstein LA, Zhou DF, Picker L, Minty CN, Bargatze RF, Ding JF, Butcher EC: A human lymphocyte homing receptor, the hermes antigen, is related to cartilage proteoglycan core and link proteins. Cell 1989, 56:1063-1072.

5. Stamenkovic I, Amiot M, Pesando JM, Seed B: A lymphocyte molecule implicated in lymph node homing is a member of the cartilage link protein family. Cell 1989, 56:1057-1062.

6. Screaton GR, Bell MV, Bell Jl, Jackson DG: The identification of a new alternative exon with highly restricted tissue expression in transcripts encoding the mouse Pgp-1 (CD44) homing receptor. Comparison of all 10 variable exons between mouse, human, and rat. J Biol Chem 1993, 268:12235-12238.

7. Screaton GR, Bell MV, Jackson DG, Cornelis FB, Gerth U, Bell Jl: Genomic structure of DNA encoding the lymphocyte homing receptor CD44 reveals at least 12 alternatively spliced exons. Proc Natl Acad Sci U S A 1992, 89:12160-12164

8. Tolg C, Hofmann M, Herrlich P, Ponta H: Splicing choice from ten variant exons establishes CD44 variability. Nucleic Acids Res 1993, 21:1225-1229.

9. Gallatin WM, Weissman IL, Butcher EC: A cell-surface molecule involved in organ-specific homing of lymphocytes. Nature 1983, 304:30-34.

10. Haegel H, Dierich A, Ceredig R: CD44 in differentiated embryonic stem cells: surface expression and transcripts encoding multiple variants. Dev Immunol 1994, 3:239-246.

11. Du L, Wang H, He L, Zhang J, Ni B, Wang X, Jin H, Cahuzac N, Mehrpour M, Lu Y, Chen Q: CD44 is of functional importance for colorectal cancer stem cells. Clin Cancer Res 2008, 14:6751-6760.

12. Ponti D, Costa A, Zaffaroni N, Pratesi G, Petrangolini G, Coradini D, Pilotti S, Pierotti MA, Daidone MG: Isolation and in vitro propagation of tumorigenic breast cancer cells with stem/progenitor cell properties. Cancer Res 2005, 65:5506-5511.

13. Patrawala L, Calhoun T, Schneider-Broussard R, Li H, Bhatia B, Tang S, Reilly JG, Chandra D, Zhou J, Claypool K: Highly purified CD44+ prostate cancer cells from xenograft human tumors are enriched in tumorigenic and metastatic progenitor cells. Oncogene 2006, 25:1696-1708

14. Haynes $\mathrm{BF}$, Liao HX, Patton $\mathrm{KL}$ : The transmembrane hyaluronate receptor (CD44): multiple functions, multiple forms. Cancer Cells 1991, 3:347-350.

15. Mima K, Okabe H, Ishimoto T, Hayashi H, Nakagawa S, Kuroki H, Watanabe M, Beppu T, Tamada M, Nagano O: CD44s regulates the TGF-beta-mediated mesenchymal phenotype and is associated with poor prognosis in patients with hepatocellular carcinoma. Cancer Res 2012, 72:3414-3423.

16. Ryu HS, Park SH, Lee KB, Shin E, Jang JJ: Expression of the Transmembrane Glycoprotein CD44s is Potentially an Independent Predictor of Recurrence in Hepatocellular Carcinoma. Gut Liver 2011, 5:204-209.

17. Zhang J, Chang B, Liu J: CD44 standard form expression is correlated with high-grade and advanced-stage ovarian carcinoma but not prognosis. Hum Pathol 2013, 44:1882-1889.

18. Brown RL, Reinke LM, Damerow MS, Perez D, Chodosh LA, Yang J, Cheng C: CD44 splice isoform switching in human and mouse epithelium is essential for epithelial-mesenchymal transition and breast cancer progression. J Clin Invest 2011, 121:1064-1074.

19. Afify AM, Tate S, Durbin-Johnson B, Rocke DM, Konia T: Expression of CD44s and CD44v6 in lung cancer and their correlation with prognostic factors. Int J Biol Markers 2011, 26:50-57.
20. Costa WH, Rocha RM, Cunha IW, Guimaraes GC, Zequi Sde C: Immunohistochemical expression of CD44s in renal cell carcinoma lacks independent prognostic significance. Int Braz J Urol 2012, 38:456-465.

21. Dome B, Somlai B, Ladanyi A, Fazekas K, Zoller M, Timar J: Expression of CD44v3 splice variant is associated with the visceral metastatic phenotype of human melanoma. Arch: Int J Oral Maxillofac Pathol 2001, 439:628-635.

22. Sun BS, Li Y, Zhang ZF, You J, Wang CL: Osteopontin combined With CD44v6, a novel prognostic biomarker in non-small cell lung cancer undergoing curative resection. Ann Thorac Surg 2013, 96:1943-1951.

23. Shi J, Zhou Z, Di W, Li N: Correlation of CD44v6 expression with ovarian cancer progression and recurrence. BMC Cancer 2013, 13:182.

24. Saito $\mathrm{S}$, Okabe $\mathrm{H}$, Watanabe $\mathrm{M}$, Ishimoto $\mathrm{T}$, Iwatsuki $\mathrm{M}$, Baba $\mathrm{Y}$, Tanaka $\mathrm{Y}$, Kurashige J, Miyamoto Y, Baba H: CD44v6 expression is related to mesenchymal phenotype and poor prognosis in patients with colorectal cancer. Oncol Rep 2013, 29:1570-1578.

25. Li XD, Ji M, Wu J, Jiang JT, Wu CP: Clinical significance of CD44 variants expression in colorectal cancer. Tumori 2013, 99:88-92.

26. Hsieh HF, Yu JC, Ho LI, Chiu SC, Harn HJ: Molecular studies into the role of CD44 variants in metastasis in gastric cancer. Mol Pathol 1999, 52:25-28.

27. Gotte M, Yip GW: Heparanase, hyaluronan, and CD44 in cancers: a breast carcinoma perspective. Cancer Res 2006, 66:10233-10237.

28. Takahashi K: Restoration of CD44S in non-small cell lung cancer cells enhanced their susceptibility to the macrophage cytotoxicity. Lung Cancer 2003, 41:145-153.

29. Montgomery E, Abraham SC, Fisher C, Deasel MR, Amr SS, Sheikh SS, House M, Lilliemoe K, Choti M, Brock M: CD44 loss in gastric stromal tumors as a prognostic marker. Am J Surg Pathol 2004, 28:168-177.

30. Lazari P, Poulias H, Gakiopoulou H, Thomopoulou GH, Barbatis C, Lazaris AC: Differential immunohistochemical expression of CD44s, E-cadherin and beta-catenin among hyperplastic and neoplastic lesions of the prostate gland. Urol Int 2013, 90:109-116.

31. Gunia S, May M, Koch S, Dietel M, Erbersdobler A: Expression of CD44s in incidental prostate cancer is more strongly associated with Gleason scores on subsequent radical prostatectomies than conventional prognostic parameters. Pathobiology 2009, 76:286-292.

32. Kuo KT, Liang CW, Hsiao CH, Lin CH, Chen CA, Sheu BC, Lin MC Downregulation of BRG-1 repressed expression of CD44s in cervical neuroendocrine carcinoma and adenocarcinoma. Mod Pathol 2006, 19:1570-1577.

33. Jeffrey S, Ross M: Decreased CD44 standard form expression correlates with prognostic variables in ovarian carcinomas. Am J Clin Pathol 2001, 116:122-128.

34. Pacifico MD, Grover R, Richman PI, Daley FM, Buffa F, Wilson GD: CD44v3 levels in primary cutaneous melanoma are predictive of prognosis: assessment by the use of tissue microarray. Int $J$ Cancer 2006, 118:1460-1464.

35. Yamada Y, Itano N, Narimatsu H, Kudo T, Hirohashi S, Ochiai A, Tohnai I, Ueda M, Kimata K: CD44 variant exon 6 expressions in colon cancer assessed by quantitative analysis using real time reverse transcriptasepolymerase chain reaction. Oncol Rep 2003, 10:1919-1924.

36. Zalewski B: Levels of v5 and v6 CD44 splice variants in serum of patients with colorectal cancer are not correlated with $\mathrm{pT}$ stage, histopathological grade of malignancy and clinical features. World $J$ Gastroenterol 2004, 10:583-585.

37. Diaz LK, Zhou X, Wright ET, Cristofanilli M, Smith T, Yang Y, Sneige N, Sahin A, Gilcrease MZ: CD44 expression is associated with increased survival in node-negative invasive breast carcinoma. Clin Cancer Res 2005, 11:3309-3314

38. Foekens JA, Dall P, Klijn JG, Skroch-Angel P, Claassen CJ, Look MP, Ponta $H$ Van Putten WL, Herrlich P, Henzen-Logmans SC: Prognostic value of CD44 variant expression in primary breast cancer. Int J Cancer 1999, 84:209-215.

39. Friedrichs K, Franke F, Lisboa BW, Kugler G, Gille I, Terpe HJ, Holzel F, Maass H, Gunthert U: CD44 isoforms correlate with cellular differentiation but not with prognosis in human breast cancer. Cancer Res 1995, 55:5424-5433.

40. Tsukuda H, Matsumura Y, Inoue T, Kobayashi Y, Ookawa K, Aoki T, Nebiki H, Yamazaki O, Kondo H, Kakizoe T: Diagnostic application of CD44 variant expression in pancreatic juice for detection of pancreatic neoplasm. Anticancer Res 2001, 21:2175-2183.

41. Rall CJ, Rustgi AK: CD44 isoform expression in primary and metastatic pancreatic adenocarcinoma. Cancer Res 1995, 55:1831-1835. 
42. Tomaszewska R: [Morphologic, morphometric and immunohistochemical studies on pancreatic intraductal hyperplasia and infiltrating carcinoma]. Folia Med Cracov 1999, 40:101-141.

43. Gotoda T, Matsumura Y, Kondo H, Saitoh D, Shimada Y, Kosuge T, Kanai Y, Kakizoe T: Expression of CD44 variants and its association with survival in pancreatic cancer. Jpn J Cancer Res 1998, 89:1033-1040.

44. Konig $\mathrm{H}$, Moll J, Ponta $\mathrm{H}$, Herrlich P: Trans-acting factors regulate the expression of CD44 splice variants. EMBO J 1996, 15:4030-4039.

45. Slominski AT, Raso-Barnett L, Banky B, Barbai T, Becsagh P, Timar J, Raso E: Demonstration of a melanoma-specific CD44 alternative splicing pattern that remains qualitatively stable, but shows quantitative changes during tumour progression. PLOS One 2013, 8:e53883.

46. Sullu Y, Gun S, Atmaca S, Karagoz F, Kandemir B: Poor prognostic clinicopathologic features correlate with VEGF expression but not with PTEN expression in squamous cell carcinoma of the larynx. Diagn Pathol 2010, 5:35.

47. Zhou G, Chiu D, Qin D, Niu L, Cai J, He L, Tan D, Xu K: Expression of CD44v6 and integrin-beta1 for the prognosis evaluation of pancreatic cancer patients after cryosurgery. Diagn Pathol 2013, 8:146.

48. Ishimoto T, Nagano O, Yae T, Tamada M, Motohara T, Oshima H, Oshima M, Ikeda T, Asaba R, Yagi H: CD44 variant regulates redox status in cancer cells by stabilizing the $\mathrm{xCT}$ subunit of system $\mathrm{xc}(-)$ and thereby promotes tumor growth. Cancer Cell 2011, 19:387-400.

49. Abetamann V, Kern HF, Elsasser HP: Differential expression of the hyaluronan receptors CD44 and RHAMM in human pancreatic cancer cells. Clin Cancer Res 1996, 2:1607-1618.

50. Yasui W, Kudo Y, Naka K, Fujimoto J, Ue T, Yokozaki H, Tahara E: Expression of CD44 containing variant exon 9 (CD44v9) in gastric adenomas and adenocarcinomas: relation to the proliferation and progression. Int J Oncol 1998, 12:1253-1258.

51. Ue T, Yokozaki H, Kitadai Y, Yamamoto S, Yasui W, Ishikawa T, Tahara E: Co-expression of osteopontin and CD44v9 in gastric cancer. Int J Cancer 1998, 79:127-132.

52. Omara-Opyene AL, Qiu J, Shah GV, Iczkowski KA: Prostate cancer invasion is influenced more by expression of a CD44 isoform including variant 9 than by Muc18. Lab Invest 2004, 84:894-907.

53. Goi T, Koneri K, Katayama K, Hirose K, Yamaguchi A: Evaluation of clinicopathological factors and the correlation between the adhesion molecule CD44 variant 9 expression and pulmonary metastases from colorectal cancers. Int Surg 2002, 87:130-136.

54. Afify A, McNiel MA, Braggin J, Bailey H, Paulino AF: Expression of CD44s, CD44v6, and hyaluronan across the spectrum of normal-hyperplasiacarcinoma in breast. Appl Immunohistochem Mol Morphol 2008, 16:121-127.

55. Orian-Rousseau V, Chen L, Sleeman JP, Herrlich P, Ponta H: CD44 is required for two consecutive steps in HGF/c-Met signaling. Genes Dev 2002, 16:3074-3086.

56. Mielgo A, van Driel M, Bloem A, Landmann L, Gunthert U: A novel antiapoptotic mechanism based on interference of Fas signaling by CD44 variant isoforms. Cell Death Differ 2006, 13:465-477.

doi:10.1186/1746-1596-9-79

Cite this article as: Li et al:: CD44v/CD44s expression patterns are associated with the survival of pancreatic carcinoma patients. Diagnostic Pathology 2014 9:79.

\section{Submit your next manuscript to BioMed Central and take full advantage of:}

- Convenient online submission

- Thorough peer review

- No space constraints or color figure charges

- Immediate publication on acceptance

- Inclusion in PubMed, CAS, Scopus and Google Scholar

- Research which is freely available for redistribution

Submit your manuscript at www.biomedcentral.com/submit 